\title{
ANÁLISE TÉCNICA E AVALIAÇÃO DE TRECHOS EXPERIMENTAIS DE MISTURAS SOLO-LAMA DE CAL COM VISTAS A APLICAÇÕES EM ESTRADAS FLORESTAIS ${ }^{1}$
}

\author{
Carlos Cardoso Machado ${ }^{2}$, Reginaldo Sérgio Pereira ${ }^{3}$, Tiago Pinto da Trindade ${ }^{4}$, Dario Cardoso de Lima ${ }^{5}$, \\ Carlos Alexandre Braz de Carvalho ${ }^{5}$ e Sérgio Luis Martins Santos ${ }^{6}$
}

\begin{abstract}
RESUMO - Trechos rodoviários experimentais são ferramentas úteis para a avaliação da eficiência de material de construção de estradas. Neste artigo, apresenta-se uma avaliação do desempenho de trechos experimentais construídos com camadas de solos estabilizados com o resíduo sólido industrial denominado lama de cal, que é um subproduto gerado em indústrias de celulose. Com base nos resultados de ensaios de resistência mecânica de um extenso programa de laboratório, em que se realizaram ensaios de caracterização dos solos e estudos de dosagem das misturas, foram construídos três trechos experimentais na região de Alagoinhas, Bahia, Brasil. Em uma avaliação qualitativa desses trechos experimentais, o melhor desempenho de campo foi associado àquele construído com a mistura contendo $70 \%$ de solo cascalho de primeira e $30 \%$ do resíduo lama de cal.
\end{abstract}

Palavras-chave: Estrada florestal, lama de cal, estabilização de solo e trecho experimental.

\section{TECHNICAL ANALYSIS AND EVALUATION OF EXPERIMENTAL FIELD ROAD SITES OF SOIL-WHITEWASH MUD MIXTURES FOR FOREST ROAD APPLICATIONS}

\begin{abstract}
Experimental field road test sites are useful technical tools for evaluating the efficiency of road engineering materials. This paper is directed to the evaluation of performance of experimental field road test sites built using mixtures of in-place soils and industrial waste from the cellulose industry named whitewash mud. Analysis of data from an extensive laboratory testing program including soils geotechnical characterization and mixtures mechanical strength tests led to the construction of three experimental field road test sites in the municipality of Alagoinhas, Bahia State, Brazil. Data from a qualitative evaluation of these sites under field traffic conditions support that best performance can be associated to the road pilot test site built using mixture contents of $70 \%$ of first class gravel and $30 \%$ of whitewash mud.
\end{abstract}

Keywords: Forest road, whitewash mud, soil stabilization, experimental field road.

\footnotetext{
${ }^{1}$ Recebido em 07.07.2006 e aceito para publicação em 20.03.2007.

${ }^{2}$ Departamento de Engenharia Florestal da Universidade Federal de Viçosa. E-mail: <machado@ufv.br>.

${ }^{3}$ Departamento de Engenharia Florestal da Universidade de Brasília. E-mail: <reginaldosp@unb.br>.

${ }^{4}$ Companhia de Água e Esgoto de Brasília (CAESB) - E-mail:<tiagotrindade@ caesb.df.gov.br>

${ }^{5}$ Departamento de Engenharia Civil da Universidade Federal de Viçosa. E-mail: <declima@ufv.br>.

${ }^{6}$ Bahia Pulp. E-mail: <sergio_santos@bahiapulp.com>.
} 


\section{INTRODUÇÃO}

A pavimentação rodoviária com o uso da técnica de estabilização química de solos foi destacada por Trindade et al. (2005) como uma técnica que pode reduzir os custos com o transporte de material de jazidas de empréstimo, bem como os impactos ambientais associados com a sua exploração, tendo grande aplicação na construção de estradas florestais que têm como principais condicionantes, segundo Machado et al. (2003b), a baixa durabilidade da superfície de rolamento e a escassez de solos locais aptos para emprego como camada de revestimento primário.

Solução tecnológica, de baixo custo, para esses tipos de vias de acesso poderá vir a ser a aplicação proveitosa de resíduos industriais como estabilizantes químicos de solos locais. Nesse direcionamento, fazse menção aos estudos promissores com o alcatrão de madeira de eucalipto (MACHADO et al., 2003a), escórias de aciaria (BALTAZAR, 2001) e alto forno (SANT'ANA, 2003), cinzas volantes (CONSOLI et al., 2001), lodo do efluente (RANGEL, 1980), fosfogesso (PARREIRA et al., 2001), grits (PEREIRA, 2005) etc. Entretanto, a maioria dessas alternativas foi analisada em laboratório, não se tendo conhecimento do provável comportamento desses materiais em campo, através da realização de ensaios in situ, em que as condições climáticas exercem significativa influência. Essa constatação induz à necessidade de se executarem trechos experimentais, em campo, com posterior levantamento de defeitos e avaliação do desempenho destes, quando submetidos às intempéries climáticas e ao tráfego de veículos.

No ano de 2004, uma nova modalidade despertou o interesse para a estabilização de solos de estradas florestais. Trata-se do resíduo lama de cal da indústria de celulose, que vem sendo fruto de experiências Universidade Federal de Viçosa (UFV), desenvolvidas por Machado et al. (2004ab).

Assim, o propósito deste artigo foi analisar, em laboratório, o comportamento mecânico de misturas solo-lama de cal, bem como avaliar, em campo, o desempenho de trechos experimentais, construídos com solo de subleito local misturado com lama de cal e submetidos à ação de tráfego pesado em áreas florestais na região de Alagoinhas, BA, pertencentes à empresa de celulose BAHIA PULP S.A.

R. Árvore, Viçosa-MG, v.31, n.2, p.265-274, 2007

\section{MATERIAL E MÉTODOS}

\subsection{Identificação dos solos e do resíduo industrial}

Sete amostras de solos foram coletadas nos subleitos das estradas florestais, situadas em áreas de plantio de eucalipto da empresa de celulose BAHIA PULP S.A., que são representativas da microrregião de Alagoinhas, BA. Ressalta-se que essas amostras foram selecionadas e coletadas pela equipe de estradas e transportes florestais da referida empresa. Com base na caracterização geotécnica realizada por Machado et al. (2004b) no Laboratório de Geotecnia da UFV, chegou-se a classificação apresentada na Tabela 1, de acordo com a granulometria dos solos e com as proposições do sistema rodoviário americano Transportation Research Board (TRB). Pelo sistema TRB, tem-se que somente o solo subleito alto se enquadrou no grupo de materiais finos siltosos, sendo os demais enquadrados no grupo de material granular possuidor de índices de grupo iguais a zero, mostrando-se como material de bom a excelente comportamento para subleito de estradas. Pelo mesmo sistema, os solos do grupo A2 referem-se a areia e areias siltosas ou argilosas, apresenta-se coerência com a classificação textural; o solo cascalho de primeira (A-1-a) refere-se ao grupo das pedras britadas, pedregulhos e areias. As amostras identificadas por subleito areia e cascalho de primeira foram selecionadas para os estudos mecânicos de estabilização química, por serem distintas granulometricamente e constituírem os subleitos escolhidos para a execução dos trechos experimentais.

Empregou-se como agente estabilizante dos solos lama de cal, resíduo sólido proveniente da clarificação do licor branco, durante o ciclo de recuperação da soda cáustica no processo de extração de celulose de madeiras de eucalipto. A lama de cal é constituída por carbonato de cálcio $\left(\mathrm{CaCO}_{3}\right)$ e alguma quantidade de hidróxido de sódio $(\mathrm{NaOH})$, em torno de $0,70 \%$; possui granulometria fina, é friável e de coloração acinzentada, sendo classificada como resíduo classe II (material não inerte), segundo a NBR 10.004 (ABNT, 1987). Foi cedida pela empresa BAHIA PULP S.A., onde são geradas aproximadamente 10.000 t/ano desse resíduo. Atualmente, a lama de cal é disposta no aterro industrial da empresa. 
Tabela 1 - Classificação dos solos de Alagoinhas-BA Table 1 - Classification of soils from Alagoinhas-BA

\begin{tabular}{|c|c|c|}
\hline \multirow[t]{2}{*}{ Amostra } & \multicolumn{2}{|c|}{ Classificação } \\
\hline & Textural & $T R B$ \\
\hline Subleito Areia & areno-silto-argiloso & $A-2-4(0)$ \\
\hline Subleito Baixo & areno-silto-argiloso & A-2-4 (0) \\
\hline Subleito Alto & areno-argilo-siltoso & A-4 (3) \\
\hline $\begin{array}{l}\text { Cascalho } \\
\text { Primeira }\end{array}$ & Pedregulho areno-argilo-siltoso & A-1-a (0) \\
\hline $\begin{array}{l}\text { Cascalho } \\
\text { Segunda }\end{array}$ & Pedregulho areno-argilo-siltoso & A-2-6 (0) \\
\hline Subleito & areno-argilo-siltoso & A-2-4 (0) \\
\hline Cascalho & Pedregulho areno-argilo-siltoso & A-2-4 (0) \\
\hline
\end{tabular}

\subsection{Metodologia de laboratório}

Foram realizados ensaios de $\mathrm{CBR}_{5 \text { pontos }}$ (California Bearing Ratio) segundo a metodologia do DNIT (1994), referente à energia de compactação do ensaio Proctor intermediário, obtendo-se, assim, os parâmetros ótimos de compactação $\left(W_{o t}\right.$ e $\left.\gamma_{\text {dmax }}\right)$ e os valores de capacidade de suporte CBR e de expansão ${ }_{\mathrm{CBR}}$, dos solos subleito areia e cascalho de primeira e das misturas solo $+10 \%$ lama de cal, solo $+15 \%$ lama de cal, solo $+20 \%$ lama de cal e solo $+25 \%$ lama de cal; esses porcentuais de resíduo foram calculados em relação ao peso de solos secos. Os corpos-de-prova confeccionados não foram submetidos a períodos de cura, em função da pouca disponibilidade de solo.

\subsection{Metodologia de campo}

A área de avaliação dos trechos experimentais situase na microrregião de Alagoinhas, BA, em dois projetos pertencentes à empresa BAHIA PULP S.A. Os croquis dos três trechos experimentais avaliados encontramse ilustrados na Figura 1, na qual é possível serem visualizadas as dimensões de cada trecho, para uma espessura de camada de $20 \mathrm{~cm}$, bem como o material utilizado para a sua construção. Toda a etapa de construção dos trechos e o controle tecnológico das misturas solo-lama de cal, em campo, ficou a cargo da empresa Bahia Pulp S.A., sendo a avaliação qualitativa de defeitos ao longo dos trechos realizada seis meses após a construção (Fev. 2004); ressalta-se que os trechos foram liberados para o tráfego de caminhões pesados imediatamente após a sua construção.

A metodologia adotada para a avaliação dos trechos experimentais envolveu a análise de defeitos e a determinação do peso específico aparente seco, através de levantamento de campo. Para a análise de defeitos empregou-se como referência Baesso et al. (2003), para determinação do Índice de Condição da Rodovia Não Pavimentada (ICRNP), através da análise qualitativa dos seguintes parâmetros: (i) seção transversal imprópria, (ii) drenagem inadequada, (iii) corrugações, (iv) excesso de poeira, (v) buracos, (vi) trilhas-de-roda e (vii) perda de agregados. Os defeitos encontrados nos trechos experimentais foram identificados e anotados em um formulário de campo, para posteriormente serem inseridos nas planilhas, por meio das quais se determinaram os valores de ICRNP.

A determinação do peso específico aparente seco foi feita realizando-se orifícios de dimensões aproximadas de $120 \mathrm{~mm}$ de diâmetro por $100 \mathrm{~mm}$ de altura, distribuídos ao longo dos trechos estradais, conforme ilustração da Figura 2, sendo feitos dois furos para cada tratamento, exceto para os trechos com $100 \%$ de cascalho. Dentro de cada furo foi colocado um saco plástico fino e do tipo transparente e adicionado água até o preenchimento da sacola nas dimensões do furo; com o auxílio de uma balança, determinou-se a massa de solo retirada do furo e da água necessária para o seu preenchimento. Foi determinada, em laboratório, a umidade das amostras extraídas dos furos, chegando-se à massa seca de cada amostra. Por meio da relação entre a massa de solo seco e a massa de água que corresponde, aproximadamente, ao volume do furo, determinou-se o peso específico aparente seco para cada furo. Ressaltase que o emprego desse método se deveu a dois fatos: (a) por falta de equipamentos, como os utilizados no método do funil e areia; e (b) para verificar a aplicabilidade de um método alternativo de fácil aplicação e rapidez.

\section{RESULTADOS E DISCUSSÃO}

\subsection{Resultados dos ensaios de CBR}

Na Tabela 2, encontram-se os parâmetros ótimos de compactação $\left(W_{o t}\right.$ e $g_{\text {dmax. }}$ ) e os índices CBR e Expansão ${ }_{\mathrm{CBR}}$ dos solos e das misturas solo/lama de cal. Foi observada uma tendência de aumento no valor de umidade ótima e queda no valor do peso específico aparente seco máximo dos solos subleito areia e cascalho de primeira quando da adição da lama de cal, em razão, primeiramente, da inserção de finos provenientes desse resíduo, que alteraram a granulometria das amostras de solo, aumentando as exigências de conteúdo de água para se atingir o teor ótimo de umidade; e, também, por causa da incorporação de um material (lama de cal) de densidade específica menor do que a dos solos.

R. Árvore, Viçosa-MG, v.31, n.2, p.265-274, 2007 
Croqui Esquemático dos Trechos de Jandaíra

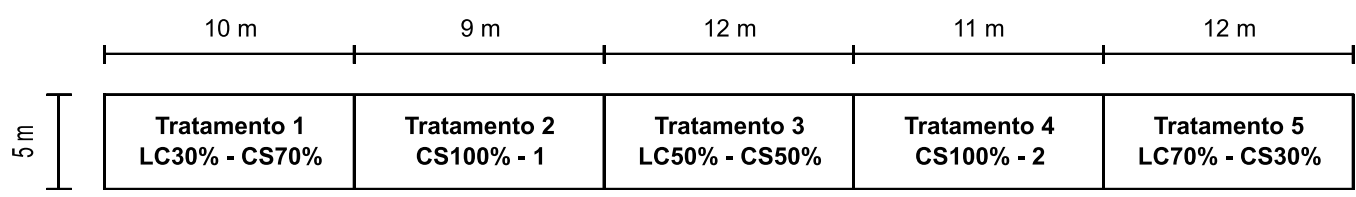

Croqui Esquemático dos Trechos de Água Boa (Baixa Intensidade de Tráfego)

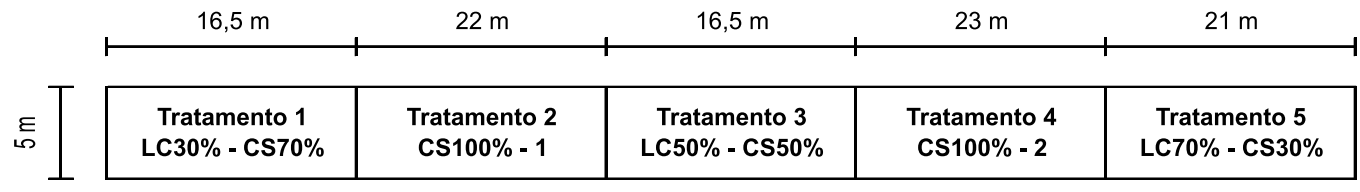

Croqui Esquemático dos Trechos de Água Boa (Alta Intensidade de Tráfego)

\begin{tabular}{|c|c|c|c|c|}
\hline \multirow{2}{*}{$20 \mathrm{~m}$} & $22 \mathrm{~m}$ & $20 \mathrm{~m}$ & $19,5 \mathrm{~m}$ \\
\hline \multirow{2}{*}{$\begin{array}{c}\text { Tratamento 1 } \\
\text { LC30\%-CS70\% }\end{array}$} & $\begin{array}{c}\text { Tratamento 2 } \\
\text { CS100\% - 1 }\end{array}$ & $\begin{array}{c}\text { Tratamento 3 } \\
\text { LC50\% - CS50\% }\end{array}$ & $\begin{array}{c}\text { Tratamento 4 } \\
\text { CS100\% - 2 }\end{array}$ & $\begin{array}{c}\text { Tratamento 5 } \\
\text { LC70\% - CS30\% }\end{array}$ \\
\hline
\end{tabular}

\begin{abstract}
Legenda:
LC 30\% - CS70\% = Combinação de 30\% do resíduo lama de cal com 70\% de cascalho de jazidas locais; CS100\% - 1 = Primeiro trecho com 100\% de cascalho de jazidas locais;

LC50\% - CS50\% = Combinação de 50\% do resíduo lama de cal com 50\% de cascalho de jazidas locais; CS100\% - 2 = Segundo trecho com 100\% de cascalho de jazidas locais; e

LC70\% - CS30\% = Combinação de 70\% do resíduo lama de cal com 30\% de cascalho de jazidas locais.
\end{abstract}

Figura 1 - Croqui dos trechos experimentais avaliados.

Figure 1 - Drawing of the experimental field road sites evaluation.

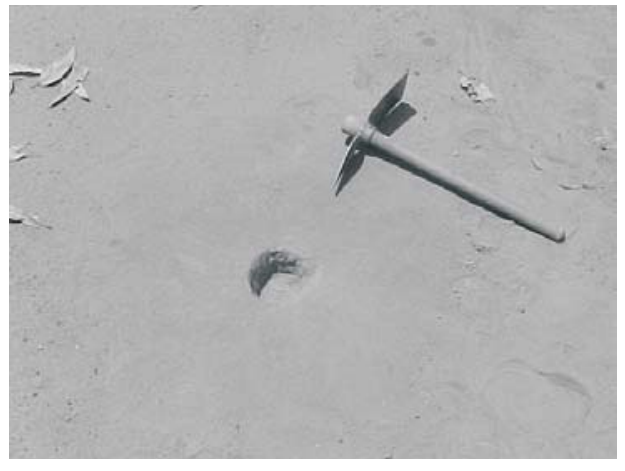

(a)

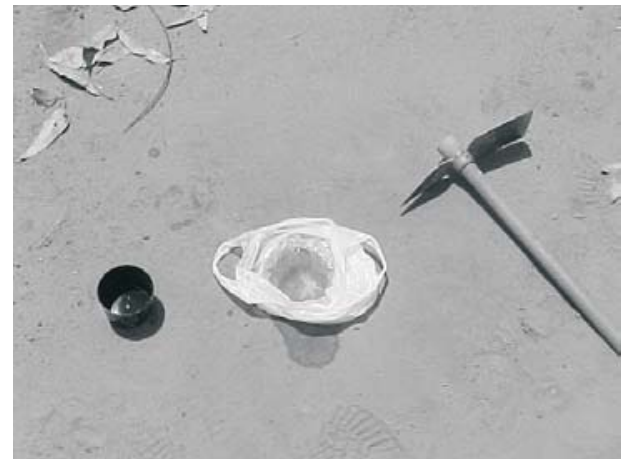

(b)

Figura 2 - Aspectos gerais (a) e sacola plástica preenchida com água (b) nos orifícios para a determinação da densidade específica aparente seca nos trechos experimentais.

Figure 2-General aspect (a) and plastic bag fulfilled with water (b) into the holes to determine the specific dry density for the experimental field road sites.

R. Árvore, Viçosa-MG, v.31, n.2, p.265-274, 2007 
Tabela 2 - Resultados dos ensaios de CBR do ensaio Proctor intermediário

das amostras de solo e misturas solo-lama de cal compactadas na energia

Table 2 - Result for CBR ${ }_{5 p o i n t}$ assay of the soil samples and soil-whitewash mud compacted in the intermediary Proctor effort

\begin{tabular}{|c|c|c|c|c|}
\hline \multirow[t]{2}{*}{ Misturas } & \multicolumn{2}{|c|}{ Compactação } & \multicolumn{2}{|c|}{$\mathrm{CBR}$} \\
\hline & $W_{o t}(\%)$ & $\gamma_{d \max }\left(k N / m^{3}\right)$ & $C B R(\%)$ & $\operatorname{Exp}_{C B R}(\%)$ \\
\hline Subleito Areia sem LC & 8,10 & 16,66 & 26,40 & 0,04 \\
\hline Subleito Areia $+10 \% \mathrm{LC}$ & 8,20 & 15,97 & 12,50 & 0,10 \\
\hline Subleito Areia $+15 \% \mathrm{LC}$ & 10,00 & 16,25 & 11,30 & 0,16 \\
\hline Subleito Areia $+20 \% \mathrm{LC}$ & 11,40 & 17,05 & 27,30 & 0,26 \\
\hline Subleito Areia $+25 \%$ LC & 10,80 & 16,56 & 11,40 & 0,48 \\
\hline Cascalho de Primeira sem $L C$ & 11,05 & 18,04 & 35,50 & 1,03 \\
\hline Cascalho de Primeira $+10 \% \mathrm{LC}$ & 10,40 & 16,26 & 23,00 & 0,21 \\
\hline Cascalho de Primeira $+15 \%$ LC & 11,20 & 15,73 & 27,00 & 0,22 \\
\hline Cascalho de Primeira $+20 \% \mathrm{LC}$ & 11,40 & 17,93 & 40,50 & 0,88 \\
\hline Cascalho de Primeira $+25 \%$ LC & 11,80 & 18,08 & 52,00 & 0,10 \\
\hline
\end{tabular}

Com relação à resistência mecânica e à expansão das misturas solo/lama de cal, os resultados da Tabela 2 indicam que: (i) Para a maioria das misturas subleito areia/lama de cal foram encontrados valores de CBR menores do que o do solo em sua forma natural, à exceção da mistura com $20 \%$ de lama de cal, que atingiu valor de CBR (27\%), praticamente similar ao valor do solo subleito areia $(\mathrm{CBR}=26 \%)$. Tal fato ocorreu devido à granulometria arenosa desse solo e, também, à grande concentração de matéria orgânica observada nessa amostra, o que provavelmente impediu a estabilização com a lama de cal; o teor de $20 \%$ de lama de cal foi o que promoveu melhor arranjo entre as partículas do solo, favorecendo a melhor compactação e, conseqüentemente, maior resistência mecânica. Os valores de expansão desse solo aumentaram devido à adição da lama de cal, entretanto podem ser considerados de pequena monta, à luz das recomendações do DNIT (1996), para a pavimentação rodoviária. (ii) Para as misturas cascalho de primeira/lama de cal com 20 e $25 \%$ de resíduo, respectivamente, foram observados valores de CBR de 40 e $52 \%$, superiores ao valor do solo cascalho de primeira $(\mathrm{CBR}=35 \%)$ em sua forma natural, sendo a expansão desse solo reduzida devido à adição dos teores de lama de cal.

Ressalta-se que, em razão da não-realização de períodos de cura nos corpos-de-prova compactados no ensaio CBR, por exemplo de sete dias como recomendado para as misturas solo/cimento ou de 28 dias para as mistura solo/cal, a reatividade solo/lama de cal pode ter ficado comprometida. Acredita-se que, com a utilização de um esforço de compactação maior (energia modificada) e a execução de cura nos corposde-prova, possam ser atingidos maiores valores de resistência mecânica com as misturas solo/lama de cal.

\subsection{Avaliação dos trechos experimentais}

De posse da melhor mistura solo/lama de cal definida em laboratório, ou seja, cascalho de primeira $+25 \%$ de lama de cal, procedeu-se à execução dos trechos experimentais. Nas Figuras 3 a 5, apresentam-se os defeitos identificados nos trechos experimentais de Jandaíra, Água Boa (Baixa Intensidade de Tráfego, BIT) e Água Boa (Alta Intensidade de Tráfego, AIT), com as respectivas identificações dos defeitos observados.

Os dados elucidados na Figura 6 trazem um comparativo entre os valores do ICRNP para os tratamentos dos trechos de Jandaíra, Água Boa (BIT) e Água Boa (AIT). A partir desses resultados foi possível observar que os tratamentos LC $30 \%$ - CS $70 \%$ para os três trechos experimentais foram os que apresentaram o melhor desempenho quando comparados com os tratamentos LC 50\% - CS 50\% e LC 70\% - CS30 \%. À exceção do trecho de Jandaíra, o tratamento LC 30\% CS 70\% mostrou-se superior, em comparação com os tratamentos-testemunha T2 e T4 (CS 100\%).

Tabela 3 contém os valores dos pesos específicos aparentes secos determinados em campo. Em todos os casos, foram obtidos valores de peso específico aparente seco superiores aos de laboratório, em estudo prévio realizado pela UFV com o resíduo lama de cal da empresa Bahia Pulp S.A. Acredita-se que esse grau de compactação, superior ao encontrado em laboratório, não se deveu tão-somente ao esforço imposto pelo 
rolo compactador, mas, também, à ação do tráfego de caminhões pesados sobre os trechos experimentais, tendo em vista que a avaliação foi realizada seis meses após a construção desses trechos. A partir dos resultados, ficou evidente que o tratamento LC 70\% - CS 30\% para

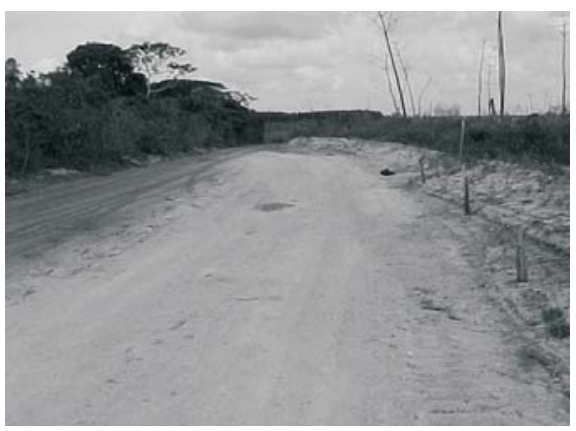

Seção transversal imprópria e drenagem inadequada, ambas de baixo nível de severidade

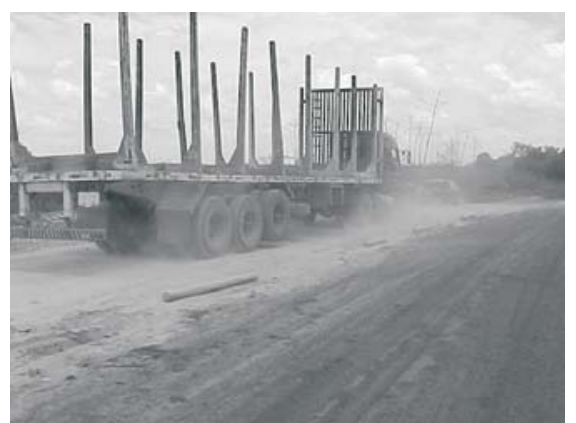

Excesso de poeira com médio nível de severidade, observado no trecho com o seguinte tratamento: LC $50 \%$ - CS $50 \%$

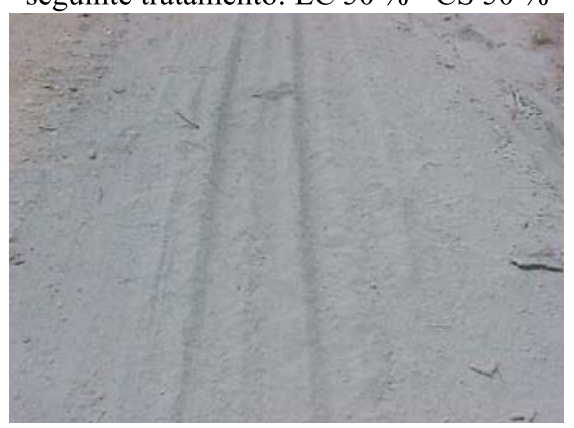

Trilhas de roda com médio nível de severidade, presentes nos trechos com os seguintes tratamentos: LC $50 \%-$ CS $50 \%$ e LC $70 \%$ - CS $30 \%$ todos os trechos experimentais não conseguiu alcançar valores de peso específico aparente seco da mesma ordem dos outros tratamentos, evidenciando-se o pouco efeito da compactação dessas misturas em termos de ganho de resistência mecânica.

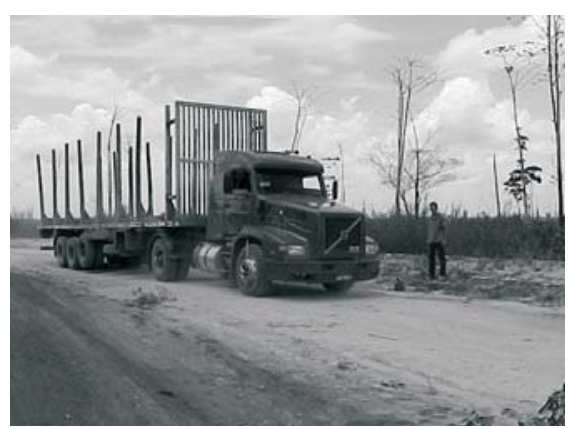

Excesso de poeira com baixo nível de severidade, observado nos trechos com os seguintes tratamentos: LC $30 \%-$ CS $70 \%$ e CS $100 \%$

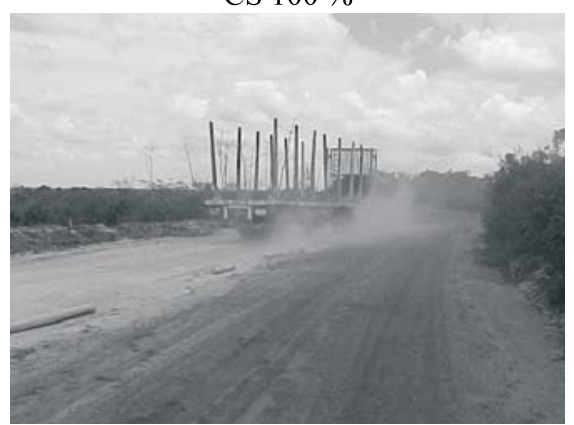

Excesso de poeira com Alto nível de severidade, observado no trecho com o seguinte tratamento: LC $70 \%$ - CS $30 \%$

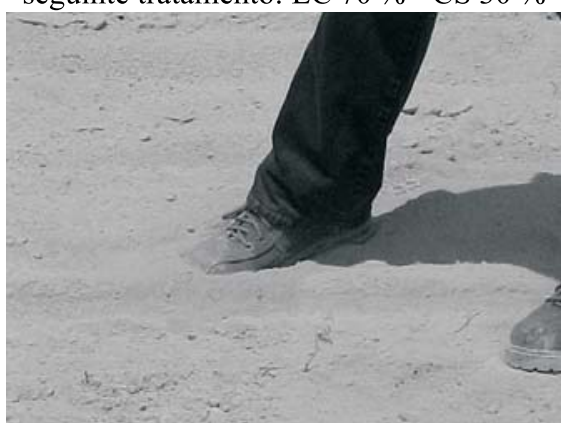

Excesso de material solto com baixa coesão, observado nos trechos com os seguintes tratamentos: LC $50 \%-\mathrm{CS} 50 \% \mathrm{e}$ LC $70 \%-$ CS $30 \%$

Figura 3 - Defeitos observados nos tratamentos do trecho de Jandaíra.

Figure 3-Defects found in the the Jandaira field road treatment. 

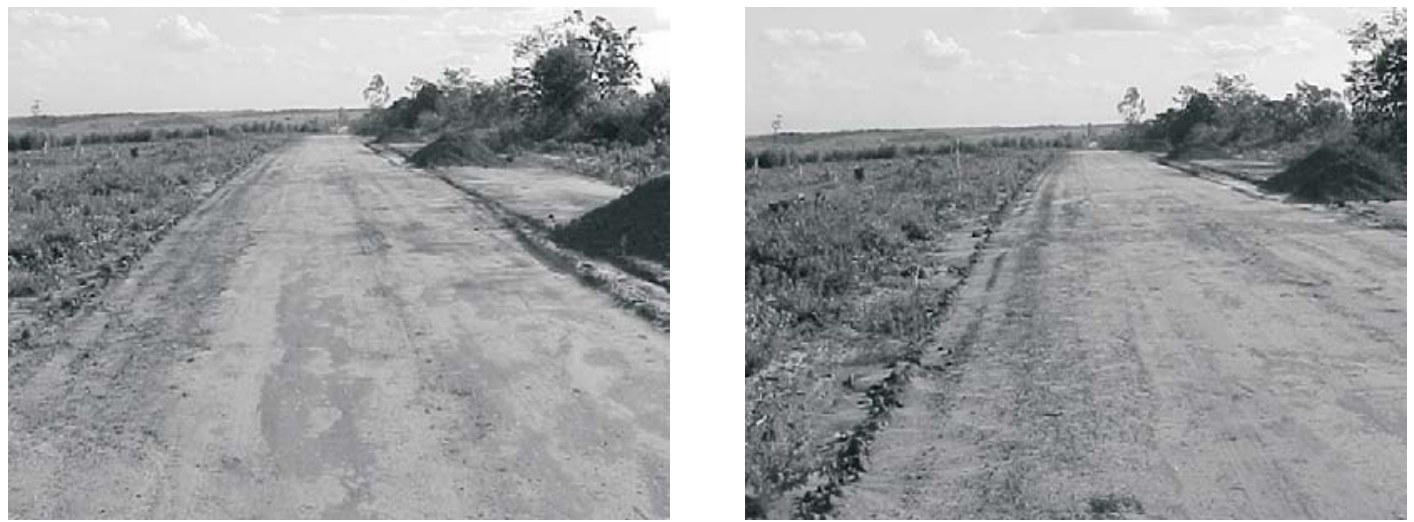

Seção transversal e drenagem, executadas de maneira correta

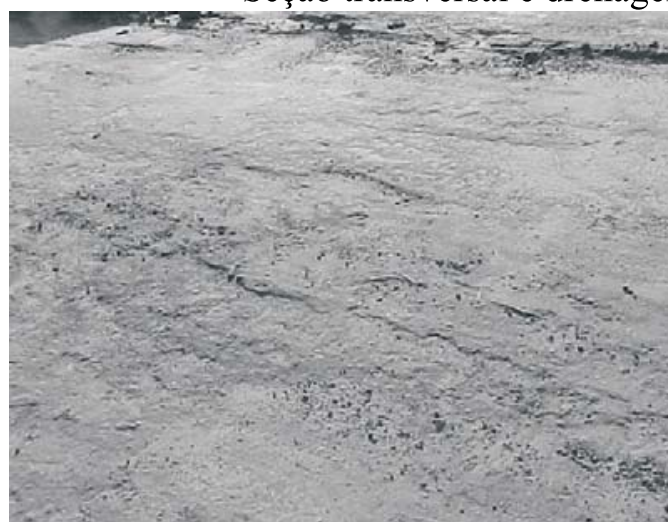

Perda de agregado de baixo nível de severidade, observada no trecho com o seguinte tratamento: CS $100 \%$

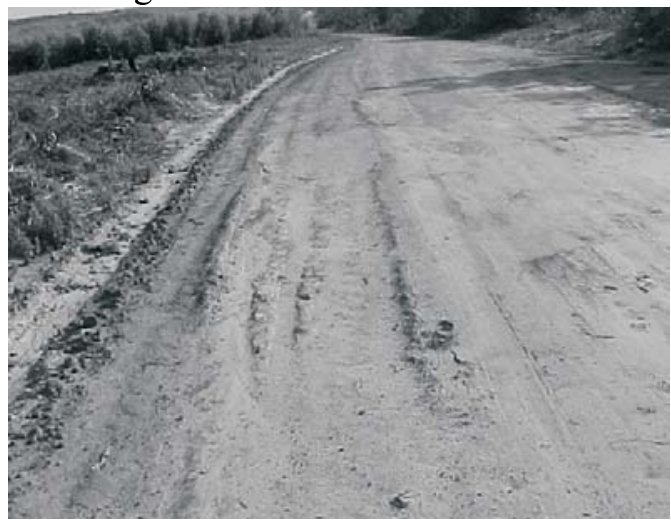

Trilhas de roda com baixo nível de severidade, presentes no trecho com o seguinte tratamento: LC $70 \%$ - CS $30 \%$

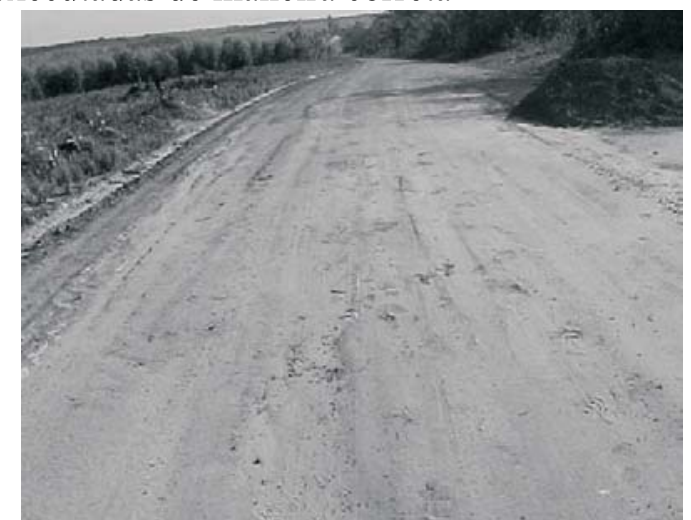

Trilhas de roda de baixo nível de severidade, observadas no trecho com o seguinte tratamento: CS $100 \%$

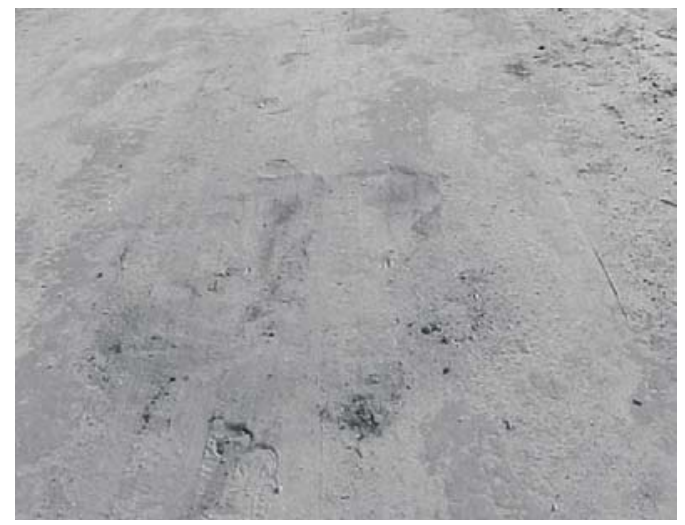

Buracos de baixo nível de severidade, encontrados nos trechos com os seguintes tratamentos: CS $100 \%$, LC $50 \%$ - CS $50 \%$ e LC $70 \%$ - CS $30 \%$

Figura 4 - Defeitos observados nos tratamentos do trecho de Água Boa - BIT.

Figure 4-Defects found in the the Água Boa-BIT field road treatment. 

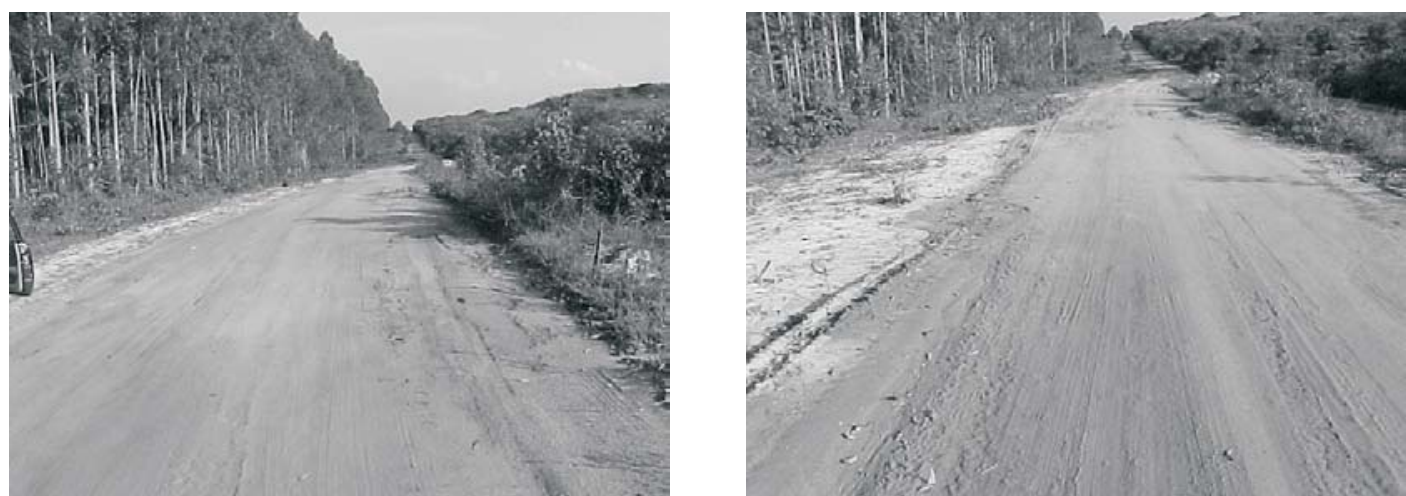

Seção transversal e drenagem executadas de maneira correta. Entretanto, o trecho com o tratamento LC $70 \%$ - CS $30 \%$ teve suas condições inicias comprometidas devido à superposição de trilhas de roda e ao afundamento da camada.

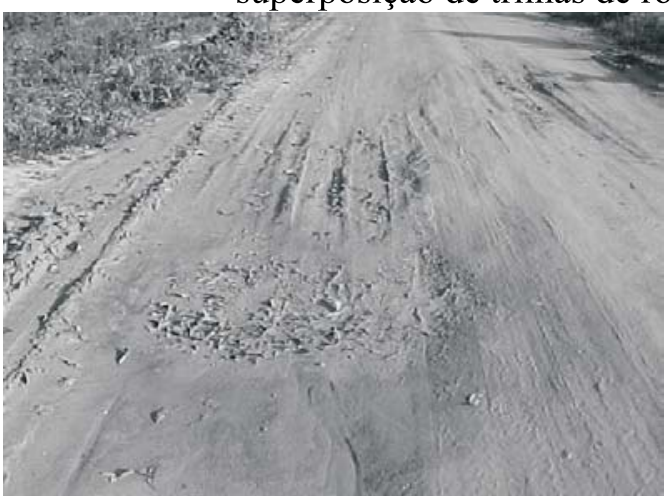

Buracos com médio nível de severidade, presentes nos trechos com os tratamentos: LC $50 \%$ - CS $50 \%$ e LC $70 \%$ - CS $30 \%$

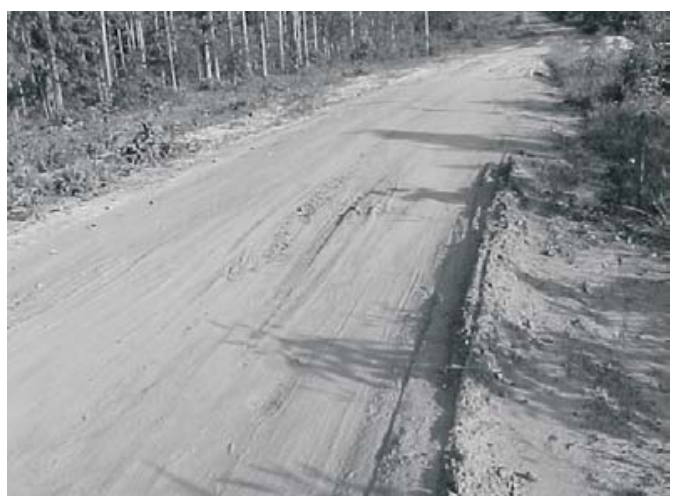

Trilha de roda com baixo nível de severidade, observada no trecho com o seguinte tratamento: LC $50 \%$ - CS $50 \%$

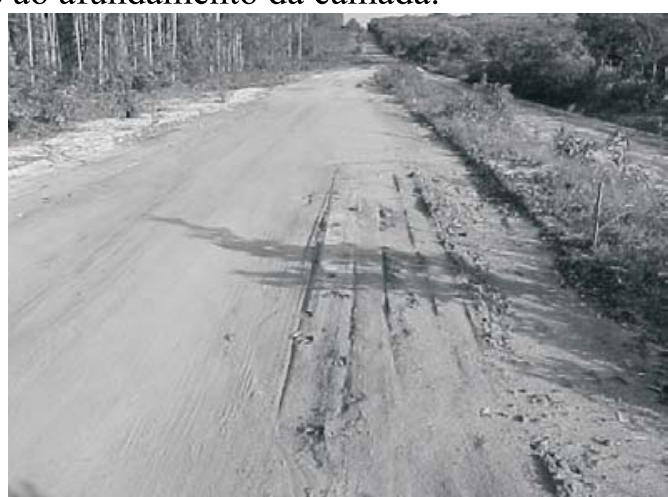

Trilhas de roda e buracos de baixo nível de severidade, observados nos trechos com os seguintes tratamentos: LC $30 \%-$ CS $70 \%$ e CS $100 \%$

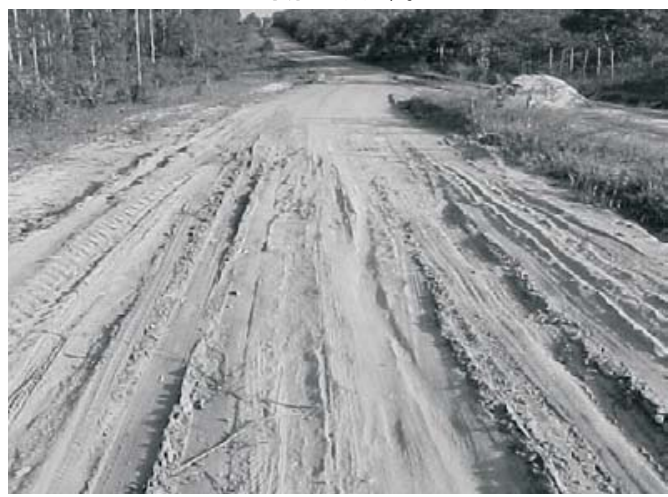

Superposição de defeitos de médio e alto nível de severidade, encontrados no trecho com o seguinte tratamento: LC $70 \%$ CS $30 \%$

Figura 5 - Defeitos observados nos tratamentos do trecho de Água Boa - AIT.

Figure 5 -Defects found in the the Água Boa-AIT field road treatment. 
Tabela 3 - Pesos específicos aparentes secos determinados nos trechos experimentais Table 3 - Specific dry density determined for the experimental road fields

\begin{tabular}{|c|c|c|c|c|c|}
\hline \multirow{2}{*}{$\begin{array}{l}\text { Trecho } \\
\text { Experimental }\end{array}$} & \multirow[t]{2}{*}{ Tratamentos } & \multicolumn{4}{|c|}{ Parâmetros determinados em campo } \\
\hline & & $\gamma_{d \text { médio }}\left(\mathrm{kN} / \mathrm{m}^{3}\right)$ & Desvio padrão $\left(\mathrm{kN} / \mathrm{m}^{3}\right)$ & $\mathrm{W}_{\text {médio }}(\%)$ & Desvio padrão(\%) \\
\hline \multirow{5}{*}{ Jandaíra } & $L C 30 \%-C S 70 \%$ & 21,65 & 1,73 & 4,19 & 0,54 \\
\hline & CS $100 \%-1$ & 19,39 & - & 2,91 & - \\
\hline & $L C 50 \%-C S 50 \%$ & 21,06 & 2,40 & 6,85 & 0,71 \\
\hline & CS $100 \%-2$ & 20,35 & - & 2,65 & - \\
\hline & $L C 70 \%-C S 30 \%$ & 18,77 & 0,97 & 7,37 & 0,84 \\
\hline \multirow{5}{*}{ Águа Воа (ВIT) } & $L C 30 \%-C S 70 \%$ & 22,60 & 1,55 & 2,64 & 0,50 \\
\hline & CS $100 \%-1$ & 20,80 & - & $2,53 *$ & - \\
\hline & $L C 50 \%-C S 50 \%$ & 22,26 & 2,29 & 3,07 & 0,42 \\
\hline & CS $100 \%-2$ & 19,36 & - & $2,34 *$ & - \\
\hline & $L C 70 \%-C S 30 \%$ & 18,78 & 1,70 & 2,10 & 0,11 \\
\hline \multirow{5}{*}{ Água Boa (BIT) } & $L C 30 \%-C S 70 \%$ & 21,51 & 0,14 & 2,57 & 0,01 \\
\hline & $C S 100 \%-1$ & $19,57 *$ & - & $2,24 *$ & - \\
\hline & $L C 50 \%-C S 50 \%$ & 20,75 & 1,22 & 2,07 & 0,32 \\
\hline & CS $100 \%-2$ & $19,53 *$ & - & $1,69^{*}$ & - \\
\hline & $L C 70 \%-C S 30 \%$ & 19,30 & 1,50 & 1,64 & 0,06 \\
\hline
\end{tabular}

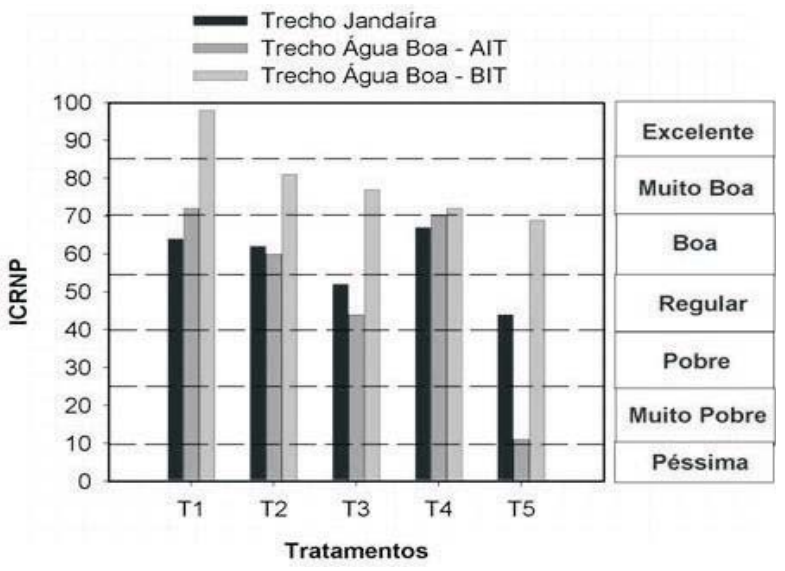

Figura 6 - Avaliação dos trechos experimentais com a lama de cal.

Figure 6-Evaluation of experimental field road sites with whitewash mud.

\section{CONCLUSÕES}

Em laboratório, as melhores respostas nas características mecânicas dos solos foram alcançadas com as misturas cascalho de primeira/lama de cal, nos traços de 20 e $25 \%$ de resíduo, em que obtiveram valores de CBR de 40 e $53 \%$, respectivamente, demonstrando o potencial do produto como estabilizante químico de solos. Em campo, em todos os trechos estradais avaliados a mistura envolvendo LC $30 \%$ - CS 70\%, ou seja, 30\% de lama de cal com $70 \%$ de cascalho mostrou-se pela análise de defeitos, como a mais promissora, visto que apresentou menos defeitos e um melhor desempenho em comparação com as demais. Além desse fato, em todos os trechos avaliados os maiores valores de peso específico aparente seco foram observados para essa mistura, evidenciando-se melhor entrosamento entre as partículas da mistura.

\section{AGRADECIMENTOS}

ÀFAPEMIG pelo apoio financeiro ao projeto, bem como à CAPES e à empresa BAHIA PULP S.A., respectivamente, pela concessão da bolsa de doutorado ao primeiro autor e fornecimento dos solos e da lama de cal.

\section{REFERÊNCIAS}

\section{ASSOCIAÇÃO BRASILEIRA DE NORMAS}

TÉCNICAS - ABNT. NBR 10.004: classificação de resíduos sólidos. Rio de Janeiro: 1987. 63p.

BAESSO, D.P.; GONÇALVES, F.L.R. Estradas Rurais: técnicas adequadas de manutenção. Florianópolis: DER-SC, 2003. 236p.

\section{BALTAZAR, R.P. Caracterização do fator} expansão de uma escória de aciaria em diferentes processos de cura para uso em pavimentação. 2001. $77 \mathrm{f}$.

Dissertação (Mestrado em Geotecnia) -

Universidade Federal de Viçosa, Viçosa, MG, 2001.

R. Árvore, Viçosa-MG, v.31, n.2, p.265-274, 2007 
CONSOLI, N.C.; PRIETTO, P.D.M.; CARRARO, J.A.H.; HEINECK, K.S. Behavior of compacted soil - flay ash - carbide lime mixtures. Journal of Geotechnical and

GeoEnvironmental Engineering, v.127, n.9, p.774-782, 2001.

\section{DEPARTAMENTO NACIONAL DE} INFRAESTRUTURA DE TRANSPORTES DNIT. ME 129: solos: compactação utilizando amostras não trabalhadas. Rio de Janeiro: 1994. 7p.

MACHADO, C.C. et al. Classificação tecnológica de solos e resíduos industriais, com e sem tratamento térmico, para fins rodoviários.

Revista Árvore, v.27, n.5, p.657-668, 2003 a.

MACHADO, C.C.; SANT'ANNA, G.L.; PEREIRA, R.S. Pavimentação de estradas florestais: emprego do alcatrão de madeira de eucalipto. Revista da Madeira, n.73, p.56-62, 2003b.

MACHADO.C.C. et al. Environmental behavior of soils and mixtures of soil - whitewash-mud.

Revista Árvore, v.28, n.3, p.459-464, 2004 a.

MACHADO, C.C. et al. Industrial solid waste (whitewash mud) use in forest road pavements. Revista Árvore, v.28, n.4, p.547-551, 2004b.
PARREIRA, A.B.; KOBAYASHI, A.R.K.; SILVESTRE JÚNIOR, O.B. Estudo da influência do tipo de cimento nas propriedades mecânicas de misturas de fosfogesso e cimento. In: REUNIÃO ANUAL DE PAVIMENTAÇÃO, 33 ., 2001, Florianópolis. Anais... Florianópolis: 2001. p.383-398.

PEREIRA, R.S. Viabilidade técnica do emprego de resíduos da indústria de celulose para construção de estradas florestais. 2005. 330f. Tese (Doutorado em Ciências Florestais)-Universidade Federal de Viçosa, Viçosa, MG, 2005.

RANGEL, A.C.R. Pavimentação de estradas florestais. Circular Técnica, IPEF, n.122, 1980.

SANT'ANA, A.P. Caracterização tecnológica de misturas solo-escória de alto forno moída para fins

rodoviários. 2003. 88f. Dissertação (Mestrado em Geotecnia) - Universidade Federal de Viçosa, Viçosa, MG, 2003.

TRINDADE, T.P. et al. Estudo da durabilidade de misturas solo-RBI Grade 81 com vistas à aplicação em estradas florestais e camadas de pavimentos convencionais. Revista Árvore, v.29, n.4, p.591-600, 2005. 